\title{
EFFECTS OF HEAT TREATMENT ON MICROSTRUCTURE AND PROPERTIES OF SELECTIVE LASER MELTED TITANIUM ALUMINIDE ALLOY
}

\author{
${ }^{1}$ Igor POLOZOV, ${ }^{1}$ Artem KANTYUKOV, ${ }^{1}$ Kirill STARIKOV, ${ }^{1}$ Anna GRACHEVA, ${ }^{2}$ Vera POPOVICH, \\ ${ }^{1}$ Anatoly POPOVICH \\ ${ }^{1}$ Peter the Great St. Petersburg Polytechnic University, St.Petersburg, Russia, polozovia@spbstu.ru \\ ${ }^{2}$ Delft University of Technology, Department of Materials Science and Engineering, Delft, The Netherlands
}

https://doi.org/10.37904/metal.2021.4076

\begin{abstract}
Titanium aluminide alloys are considered to be attractive materials for aerospace and automotive hightemperature applications due to their high specific strength, creep resistance, and heat resistance. However, their brittleness makes it difficult to manufacture complex-shaped components of these alloys using conventional processes making additive manufacturing a promising way to produce titanium aluminide parts. Additive manufacturing of titanium aluminide alloys involves high preheating temperatures affecting their microstructure; hence a proper heat treatment is needed to obtain desired properties. In this paper, a titanium aluminide alloy produced using Selective Laser Melting process with a high-temperature preheating was subjected to various heat treatments to study their effects on microstructure and properties of the alloy.
\end{abstract}

Keywords: Selective laser melting, additive manufacturing, titanium aluminide, heat treatment

\section{INTRODUCTION}

Gamma titanium aluminide ( $\mathrm{Y}$-TiAl)-based alloys are considered to be attractive materials for aerospace applications due to their high specific strength at room and elevated temperatures, as well as good oxidation resistance $(1,2)$. Ti-48Al-2Cr-2Nb alloy has been used in aero-engine turbine blades for service temperature up to $700{ }^{\circ} \mathrm{C}$ (3). While TiAl alloys possess high strength, their poor ductility and brittleness at room temperatures severely complicate their processability by conventional manufacturing techniques and limit their application (4).

One of the promising ways to produce complex parts of titanium aluminides is additive manufacturing (AM) since it reduces machining to a minimum degree and allows obtained parts with a complex shape $(5,6)$. However, high residual stresses typical for most common AM processes promote cracks formation in TiAlalloys $(7,8)$. Usually, high-temperature preheating is required to obtain crack-free intermetallic parts (9). Selective Electron Beam Melting (SEBM) has been proved feasible in fabrication of TiAl alloys (2). Utilizing an electron beam to preheat the powder bed to temperatures around $1000^{\circ} \mathrm{C}$ allows to drastically reduce residual stresses and suppress crack formation during the fabrication of TiAl alloys. Selective Laser Melting (SLM) with a high-temperature substrate preheating has also shown some promising results in producing crack-free TiAlalloys (10-12). While it is possible to reduce cracking during the SLM of TiAl-alloys with a substrate preheated to temperatures above $800-900^{\circ} \mathrm{C}$, the microstructure of the alloy might require additional heat treatment to achieve better properties.

In this paper, a titanium aluminide alloy produced using Selective Laser Melting process with a hightemperature preheating was subjected to various heat treatments to study their effects on microstructure and properties of the alloy. 


\section{MATERIALS AND METHODS}

Ti-48Al-2Cr-2Nb (at. \%) alloy gas atomized (GA) spherical powder (Figure 1) was used as the feedstock material to fabricate the samples. The powder had the following particle size distribution: $d_{10}=17.4 \mu \mathrm{m}$, $d_{50}=$ $33.8 \mu \mathrm{m}, \mathrm{d}_{90}=60.5 \mu \mathrm{m}$.

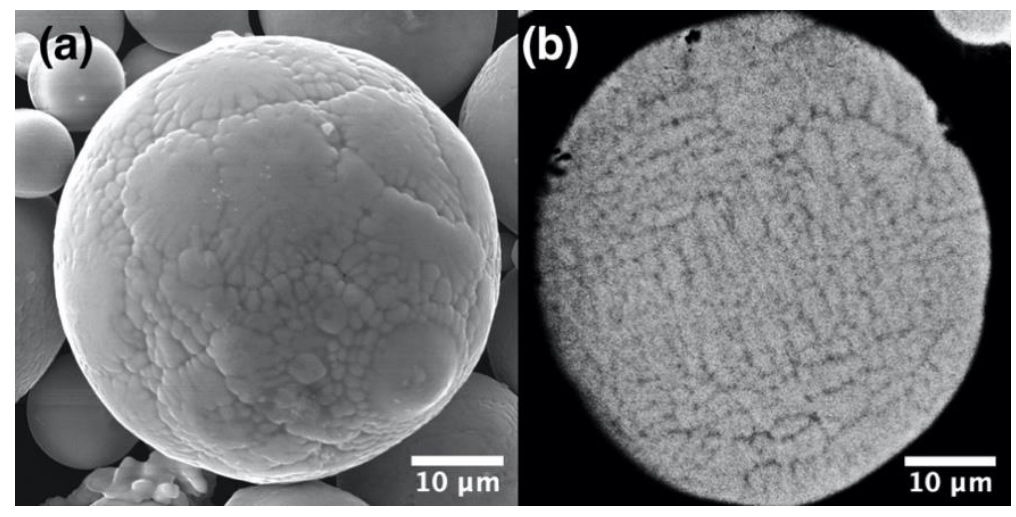

Figure 1 SEM images of the gas atomized powder (GA) showing (a) surface morphology and (b) crosssection of a particle.

The samples were manufactured by the SLM process using AconityMIDI (Aconity3D GmbH, Germany) system equipped with a $1070 \mathrm{~nm}$ wavelength fiber laser with a maximum power of $1000 \mathrm{~W}$. Cylindrical samples with $8 \mathrm{~mm}$ diameter and $15 \mathrm{~mm}$ height were fabricated for the investigation. The samples were fabricated on a Ti$6 \mathrm{Al}-4 \mathrm{~V}$ substrate, which was put on a molybdenum platform. The molybdenum substrate was inductively preheated to a set temperature, which was continuously controlled by a thermocouple under the molybdenum platform. The titanium substrate was then conductively heated by the molybdenum substrate before starting the L-PBF process. The process chamber was continuously flooded with high purity argon gas to achieve oxygen content in the chamber below $20 \mathrm{ppm}$. After the build process was finished, the platform and the samples were cooled down to room temperature with a cooling rate of approximately $5{ }^{\circ} \mathrm{C} / \mathrm{min}$. The samples were produced using $900^{\circ} \mathrm{C}$ substrate preheating temperature and $48 \mathrm{~J} / \mathrm{mm}^{3}$ volume energy density since these parameters allow to achieve fully-dense material according to the previous research (11).

Heat treatment of the samples was carried out using a Carbolite Gero vacuum furnace. Two heat treatment regimes were used: 1) below the $\alpha$-transus (or $y$-solvus) temperature at $1250^{\circ} \mathrm{C}$ for $2 \mathrm{~h}$ which corresponds to the $\alpha+y$ phase field; 2) above the $\alpha$-transus temperature at $1350^{\circ} \mathrm{C}$ for $2 \mathrm{~h}$ in the single $\alpha$-phase region. Furnace cooling was used for both of the regimes.

The as-fabricated samples were cut and polished along the build direction (BD) for the microstructural characterization. Mira 3 LMU TESCAN scanning electron microscope (SEM) in backscattered electrons (BSE) mode was utilized to evaluate the microstructures. Energy Dispersive Spectroscopy (EDS) was used for the chemical analysis of the samples and powders on the polished cross-sections. The phase composition of the powders and the fabricated samples was analyzed with a Bruker D8 Advance X-ray diffraction (XRD) using Cu-Ka $(\lambda=1.5418 \AA)$ irradiation.

Room temperature compression tests were performed using a universal testing machine (Zwick/Roell Z100, Germany) with a strain rate of $0.1 \mathrm{~mm} / \mathrm{min}$. A minimum of three samples per point were tested.

\section{RESULTS AND DISCUSSION}

Figure 2 shows the microstructure of the sample in the as-fabricated condition. The obtained microstructure is very fine and consists mainly of lamellar $\alpha 2 / \gamma$ colonies and $\alpha 2$-grains ( $\gamma$-phase appears dark, while $\alpha 2$-phase shows a light contrast). Crescent-shaped melt pool boundaries with a width of about $80-90 \mu \mathrm{m}$ can be 
distinguished in the BSE-images as can be seen in Figure 2 (a). Some amounts of retained metastable $\beta$ phase might also be present in the alloy obtained by SLM due to high cooling rates during the SLM process, however the XRD results (Figure 3) showed that only $y$ and $\alpha 2$ phases were found in the material.

The substrate preheating temperature of $900{ }^{\circ} \mathrm{C}$ during the SLM corresponds to $\alpha 2+\gamma$ phase field. During the laser melting of powder material and subsequent solidification the Ti-48Al-2Cr-2Nb alloy solidifies through the $\alpha$-region, then $y$-phase starts to nucleate, and the order-disorder transition from a to a2 occurs. Additionally, due to partial Al evaporation during the SLM process coupled with high cooling rates some residual $\beta$-phase might form in the material. The SLM process involves complex thermal history of the material characterized by repetitive heating and cooling of the solidified material. Laser melting of the powder layer leads to heating of the underlying solidified material. This leads to heating of the alloy above the eutectoid temperature in the $\alpha+\gamma$ phase field resulting in the formation of fine $\alpha 2+\gamma$ colonies.

(a)

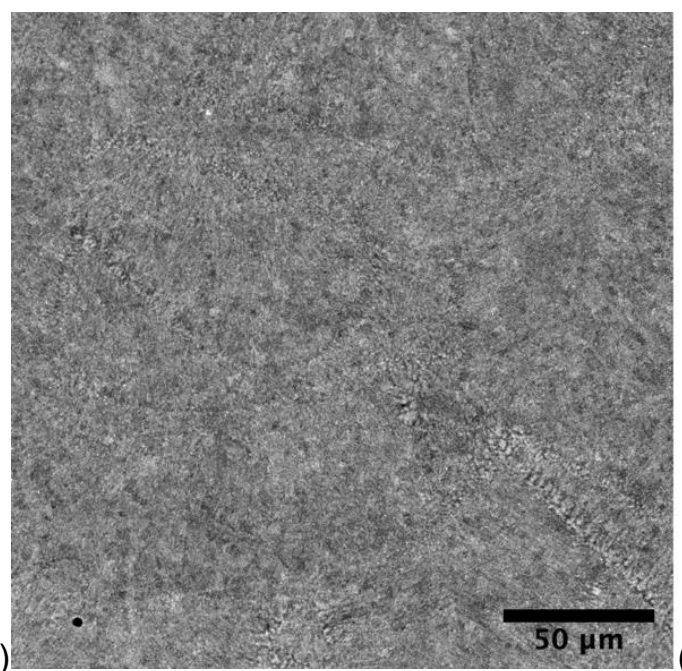

Figure 2 BSE-SEM-images of the TiAl-alloy sample fabricated by SLM

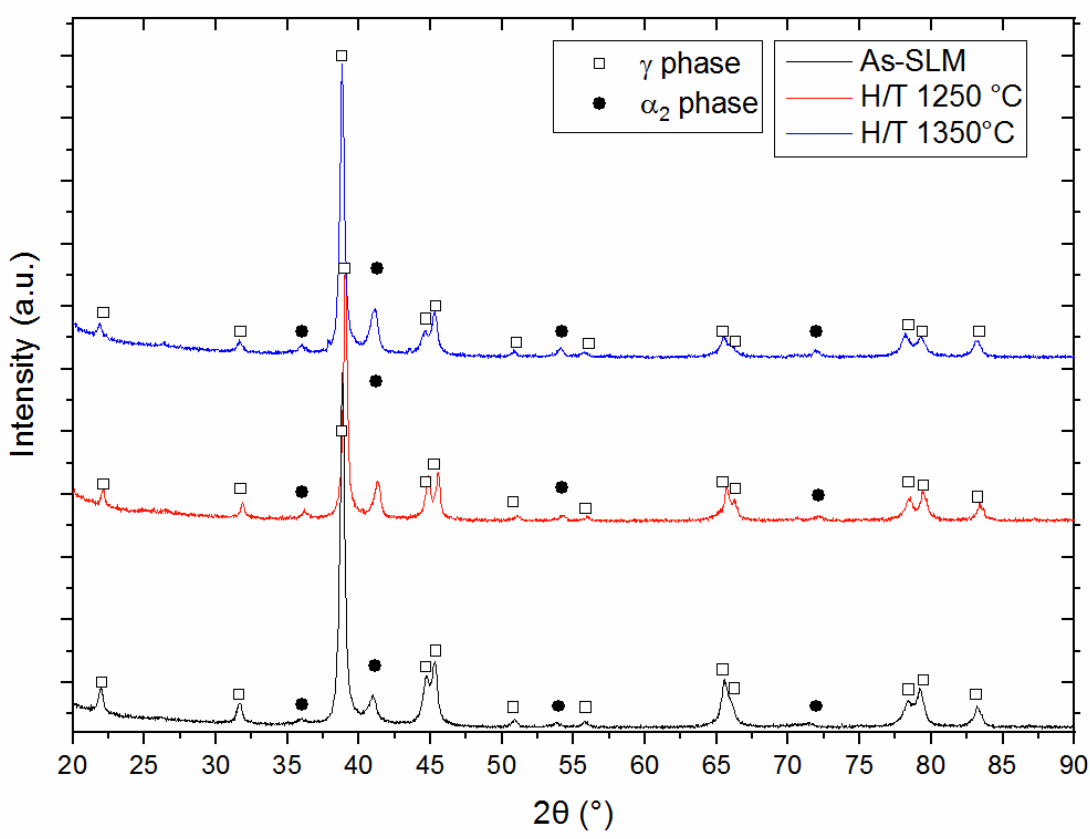

Figure 3 The XRD patterns of TiAl-samples in the as-fabricated and heat-treated states 
Microstructure of TiAl-based alloys is very sensitive to process conditions and chemical composition of the alloy. Depending on the phase composition and morphology, microstructure of TiAl-alloys can usually be characterized as fully lamellar, near lamellar, duplex, and near gamma (13). Mechanical properties of TiAlalloys can be tailored depending of the type of microstructure and their service conditions. For example, duplex microstructure demonstrates better room temperature ductility, but lower creep resistance compared to fully lamellar microstructure. Near lamellar microstructure is considered to be the most favorable for hightemperature applications since it provides balanced room temperature and creep resistance at elevated temperatures. Thus, a postprocessing treatment is necessary to modify the microstructure of the alloy.

Figure 4 shows BSE-SEM images of the sample after heat treatment at $1250^{\circ} \mathrm{C}$ for 2 hours. This temperature corresponds to $\alpha+\gamma$ phase region and is a little above the eutectoid temperature according to the binary Ti-Al phase diagram (14). Annealing the material above the eutectoid temperature resulted in the formation of a near gamma microstructure. In this case, the microstructure consists of equiaxed $y$-phase grains with a size of about $7 \mu \mathrm{m}$ (a dark contrast) and some amount of $\alpha 2$-phase (a bright contrast). The content of $\alpha 2$-phase can be varied by adjusting the annealing temperature. In the case of $1250^{\circ} \mathrm{C}$, the volume content of $\alpha 2$-phase is roughly $30 \%$ according to microstructure images analysis. Near gamma microstructure of TiAl-based alloys is characterized by an improved room temperature ductility, but inferior creep properties. Hence, this heat treatment temperature might be not optimal for high-temperature applications.
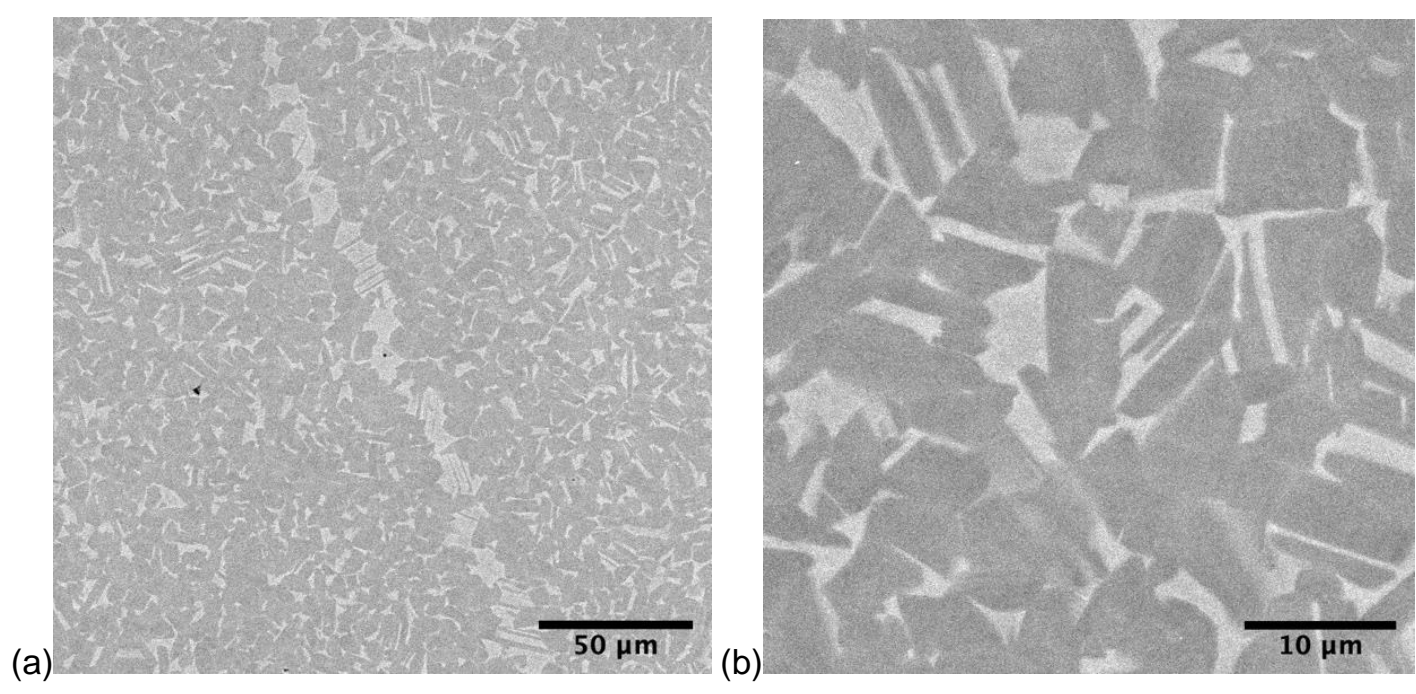

Figure 4 SEM-images of the TiAl-alloy sample fabricated by SLM after heat treatment at $1250^{\circ} \mathrm{C}$.

When annealing temperature was increased to $1350{ }^{\circ} \mathrm{C}$, the microstructure of the TiAl-alloy changed to lamellar morphology (Figure 5) with $\alpha 2 / y$ phase lamellas located within colonies. The annealing temperature of $1350^{\circ} \mathrm{C}$ is above $\alpha$-transus for the studied TiAl-based alloy and results in the formation of fully lamellar microstructure. The colonies size is around $300 \mu \mathrm{m}$, while the lamellar spacing is $0.5-1.0 \mu \mathrm{m}$.

Lamellar microstructure of TiAl-based alloys is characterized by relatively high creep resistance and fracture toughness compared to duplex or near gamma microstructures. At the same time, fully or near lamellar microstructures suffer from poor ductility. Thus, heat treatment temperature should be chosen based on specific requirements for material properties and its working conditions. For improved high-temperature performance of the SLM-ed TiAl-based alloy annealing at temperatures slightly above $\alpha$-transus is recommended as fully lamellar microstructure is expected to exhibit higher creep resistance compared to asachieved fine duplex microstructure or near-gamma microstructure after annealing at temperatures below $\alpha$ transus. 
(a)
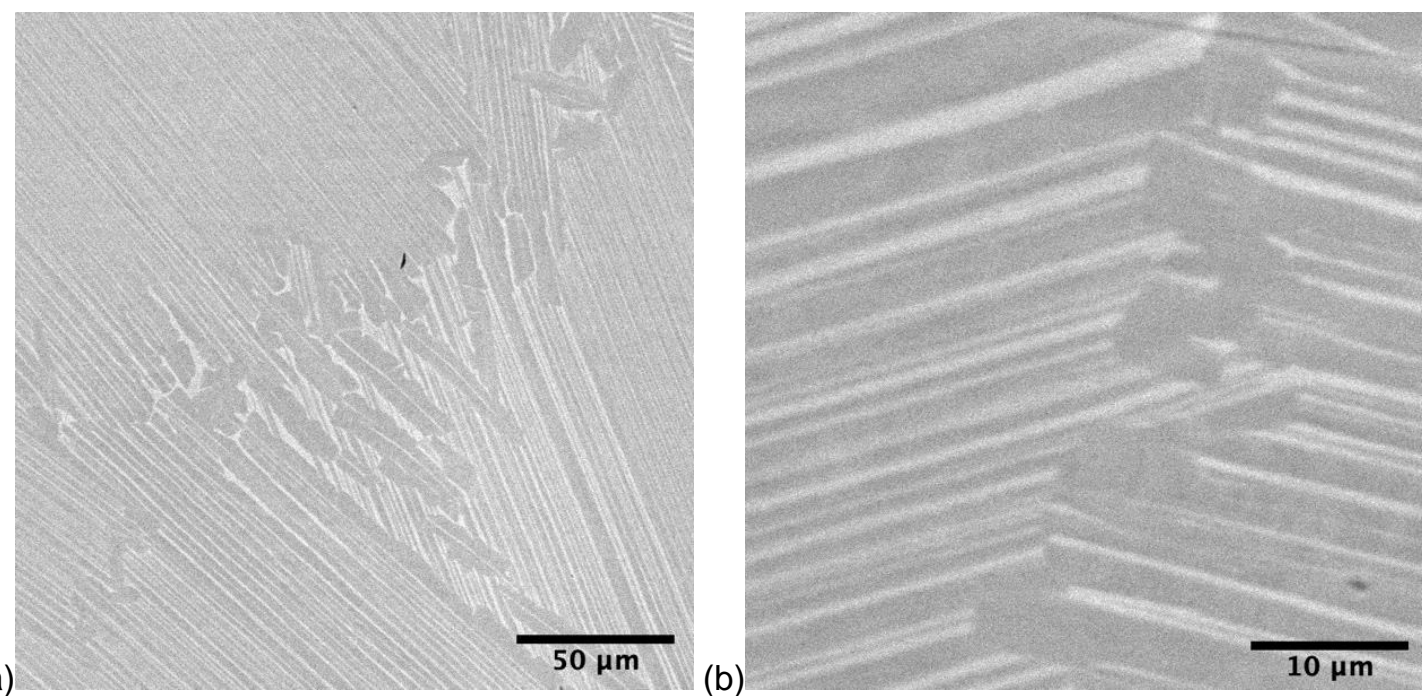

Figure 5 SEM-images of the TiAl-alloy sample fabricated by SLM after heat treatment at $1350{ }^{\circ} \mathrm{C}$.

Compressive tests at room temperature (Table 1) showed that annealing at $1250{ }^{\circ} \mathrm{C}$ resulted in highest compressive strength of the alloy, which corresponds to near-gamma microstructure and the highest volume fraction of $\alpha 2$-phase. At the same, near-gamma microstructure showed the highest values of deformation which is in a good agreement with the literature data (13) according to which the near-gamma microstructure features an improved room temperature ductility compared to lamellar-type of structure. For future investigations, creep tests should be carried out to investigate the effects of heat treatment regimens on high-temperature behavior of SLM-ed TiAl-alloys.

Table 1 Results of room temperature compressive tests of TiAl-based samples.

\begin{tabular}{|l|l|l|}
\hline Material & Ultimate compressive strength, MPa & Compressive strain, \% \\
\hline As-SLM & $1690 \pm 70$ & $24.3 \pm 1.5$ \\
\hline Annealing at $1250^{\circ} \mathrm{C}$ & $1740 \pm 20$ & $34.4 \pm 1.0$ \\
\hline Annealing at $1350^{\circ} \mathrm{C}$ & $1380 \pm 40$ & $27.5 \pm 1.5$ \\
\hline
\end{tabular}

\section{CONCLUSION}

In this paper, a titanium aluminide alloy produced using Selective Laser Melting process with a hightemperature preheating was subjected to various heat treatments to study their effects on microstructure and properties of the alloy.

The as-fabricated TiAl-based alloy exhibited very fine duplex microstructure. Depending on the annealing temperature, near-gamma or fully lamellar microstructure was obtained. Near-gamma microstructure of the alloy showed the highest values of room temperature compressive strength and strain. For future investigations, creep tests should be carried out to investigate the effects of heat treatment regimens on hightemperature behavior of SLM-ed TiAl-alloys.

\section{ACKNOWLEDGEMENTS}

This research was supported by Russian Science Foundation grant (project No 19-79-30002). 


\section{REFERENCES}

[1] MURR, L.E., GAYTAN, S.M., CEYLAN, A., MARTINEZ, E., MARTINEZ, J.L., HERNANDEZ, D.H., ET AL. Characterization of titanium aluminide alloy components fabricated by additive manufacturing using electron beam melting. Acta Mater. 2010 Mar; vol. 58, no. 5, pp. 1887-94.

[2] BAUDANA, G., BIAMINO, S., UGUES, D., LOMBARDI, M., FINO, P., PAVESE, M., et al. Titanium aluminides for aerospace and automotive applications processed by Electron Beam Melting: Contribution of Politecnico di Torino. Met Powder Rep. 2016; vol. 71, no. 3, pp. 193-9.

[3] BARTOLOTTA, P., BARRETT, J., KELLY, T., SMASHEY, R. The use of cast Ti-48Al-2Cr-2Nb in jet engines. JOM. 1997 May, vol. 49, no. 5, pp. 48-50.

[4] GUPTA, R.K., PANT, B., SINHA, P.P. Theory and Practice of $\mathrm{y}+\alpha 2$ Ti Aluminide: A Review. Trans Indian Inst Met. 2014 Apr, vol. 13; no. 67, pp. 143-65.

[5] BAUDANA, G., BIAMINO, S., KLÖDEN, B., KIRCHNER, A., WEIßGÄRBER, T., KIEBACK, B., ET AL. Electron Beam Melting of Ti-48Al-2Nb-0.7Cr-0.3Si: Feasibility investigation. Intermetallics. 2016, vol. 73, pp. 43-9.

[6] GAO, W., ZHANG, Y., RAMANUJAN, D., RAMANI, K., CHEN, Y., WILLIAMS, C.B., ET AL. The status, challenges, and future of additive manufacturing in engineering. Comput Des. 2015 Dec, vol. 69, pp. 65-89.

[7] MOHANTY, S., HATTEL, J.H. Reducing residual stresses and deformations in selective laser melting through multilevel multiscale optimization of cellular scanning strategy. Proceedings of SPIE. [online]. 2016. p. $97380 Z$. Available from: https://doi.org/10.1117/12.2212490.

[8] SHI, X., MA, S., LIU, C., WU, Q. Parameter optimization for Ti-47AI-2Cr-2Nb in selective laser melting based on geometric characteristics of single scan tracks. Opt Laser Technol. 2017, vol. 90(December 2016), pp. 71-9.

[9] GUSSONE, J., HAGEDORN, Y-C, GHEREKHLOO, H., KASPEROVICH, G., MERZOUK, T., HAUSMANN, J. Microstructure of $\mathrm{Y}$-titanium aluminide processed by selected laser melting at elevated temperatures. Intermetallics. 2015, vol. 66, pp. 133-40.

[10] CAPRIO, L., DEMIR, A.G., CHIARI, G., PREVITALI, B. Defect-free laser powder bed fusion of Ti-48Al-2Cr-2Nb with a high temperature inductive preheating system. J Phys Photonics. 2020 Feb, vol. 12, no. 2, p. 024001.

[11] POLOZOV, I., KANTYUKOV, A., GONCHAROV, I., RAZUMOV, N., SILIN, A., POPOVICH, V., ET AL. Additive Manufacturing of Ti-48Al-2Cr-2Nb Alloy Using Gas Atomized and Mechanically Alloyed Plasma Spheroidized Powders. Materials (Basel). 2020 Sep 7, vol. 3, no. 18, p. 3952.

[12] POLOZOV, I., SUFIIAROV, V., KANTYUKOV, A., RAZUMOV, N., GONCHAROV, I., MAKHMUTOV, T., ET AL. Microstructure, densification, and mechanical properties of titanium intermetallic alloy manufactured by laser powder bed fusion additive manufacturing with high-temperature preheating using gas atomized and mechanically alloyed plasma spheroidized powders. Addit Manuf. 2020.

[13] CLEMENS, H., MAYER, S.. Design, Processing, Microstructure, Properties, and Applications of Advanced Intermetallic TiAl Alloys. Adv Eng Mater. 2013 Apr, vol. 15, no. 4, pp. 191-215.

[14] MA, Y., CUIURI, D., HOYE, N., LI, H., PAN, Z. Characterization of In-Situ Alloyed and Additively Manufactured Titanium Aluminides. Metall Mater Trans B. 2014 Dec 5, vol. 45, no. 6, pp. 2299-303. 